Pacific Journal of Mathematics

FIXED POINT THEOREMS FOR MULTIVALUED 


\section{FIXED POINT THEOREMS FOR MULTIVALUED NONCOMPACT ACYCLIC MAPPINGS}

\section{P. M. FitzPatrick AND W. V. Petryshyn}

Let $X$ be a Frechet space, $D$ a closed convex subset of $X$, and $T: D \rightarrow 2^{X}$ an upper semicontinuous multivalued acyclic mapping. Using the Eilenberg-Montgomery Theorem and the earlier results of the authors, it is first shown that if $W \supset T(D)$ and $f: W \rightarrow D$ is a single-valued continuous mapping such that $f T: D \rightarrow 2^{X}$ is Ф-condensing, then $\boldsymbol{f} T$ has a fixed point. This result is then used to obtain various fixed point theorems for acyclic $\Phi$-condensing mappings $T: D \rightarrow 2^{X}$ under the Leray-Schauder boundary conditions in case $D=\overline{\operatorname{Int}(D)}$ and under the outward and /or inward type conditions in case Int $(D)=\varnothing$.

Introduction. Let $X$ be a Frechet space and $D$ an open or a closed convex subset of $X$. It is our object in this paper to establish fixed point theorems for not necessarily compact (e.g. condensing) multivalued acyclic mappings $T: D \rightarrow 2^{X}$ which need not satisfy the condition " $T(D) \subset D$ " but instead are required to satisfy weaker conditions of the Leray-Schauder type. Our results are based upon the Eilenberg-Montgomery Theorem [4] and upon our Lemma 1 in [16]. The fixed point theorems presented in this paper for multivalued maps in infinite dimensional spaces strengthen and extend certain fixed point theorems of Górniewicz-Granas [7] and Powers [17] for acyclic compact maps, the results for star-shaped-valued maps of Halpern [8] for compact maps and our own [16] for condensing maps, and a number of fixed point theorems for convex-valued compact and noncompact maps (see Ky Fan [5], Browder [1], Reich [18], Ma [12], Walt [20], and $[20,8,15]$ for related results and further references).

1. Let $X$ be a Frechet space. If $D \subset X$, then we will denote by $\bar{D}$ and $\partial D$ the closure and boundary of $D$, respectively.

Definition 1. If $C$ is a lattice with a minimal element, which we will denote by 0 , then a mapping $\Phi: 2^{X} \rightarrow C$ is called a measure of noncompactness provided that the following conditions hold for any $A, B$ in $2^{X}$ :

(1) $\Phi(A)=0$ if and only if $A$ is precompact.

(2) $\Phi(\overline{\operatorname{co}} A)=\Phi(A)$, where $\overline{\operatorname{co}} A$ denotes the convex closure of $A$.

(3) $\Phi(A \cup B)=\max \{\Phi(A), \Phi(B)\}$. 
It follows that if $A \subset B$, then $\Phi(A) \leq \Phi(B)$. The above notation has been used in [16, 19] and is a generalization of the set-measure [11] and the ball-measure of noncompactness [6] defined either in terms of a family of seminorms or of a single norm when $X$ is a Banach space. Specifically, if $\left\{P_{\alpha} \mid \alpha \in \mathscr{A}\right\}$ is a family of seminorms which determines the topology on $X$, then for each $\alpha \in \mathscr{A}$ and $\Omega \subset X$ we define $\gamma_{\alpha}(\Omega)=\inf \{d>0 \mid \Omega$ can be covered by a finite number of sets each of which has $P_{\alpha}$-diameter less than $d\}$, and $\chi_{\alpha}(\Omega)=\inf \left\{r>0 \mid \Omega\right.$ can be covered by a finite number of $P_{\alpha}$-balls each of which has $\boldsymbol{P}_{\alpha}$-radius less than $\boldsymbol{r}$.

Then letting $C=\{f: \mathscr{A} \rightarrow[0, \infty]\}$, with $C$ ordered pointwise, we define the set-measure of noncompactness $\gamma: 2^{X} \rightarrow C$ by $(\gamma(\Omega))(\alpha)=\gamma_{\alpha}(\Omega)$ for each $\alpha \in \mathscr{A}$ and the ball-measure of noncompactness $\chi(\Omega)$ by $(\chi(\Omega))(\alpha)$ $=\chi_{\alpha}(\Omega)$ for each $\alpha \in \mathscr{A}$ (see[15] for more details and properties of $\gamma$ and $\mathrm{X})$.

The class of mappings considered here is given by the following.

Definition 2. If $\Phi$ is a measure of noncompactness of $X$ and $D \subset X$, an upper semicontinuous (u.s.c.) mapping $T: D \rightarrow 2^{X}$ is called $\Phi$ condensing provided that if $\Omega \subset D$ and $\Phi(T(\Omega)) \geq \Phi(\Omega)$, then $\Omega$ is relatively compact.

It follows immediately that a compact mapping is $\Phi$-condensing with respect to any measure of noncompactness $\Phi$. Classes of $\Phi$-condensing mappings which are not compact have been considered in $[19,13,14,18]$. In particular, if $X$ is a Banach space, $D \subset X$ is closed, $C: D \rightarrow 2^{X}$ is compact, and $S: X \rightarrow 2^{X}$ is such that $S(x)$ is compact for each $x \in X$, and $d^{*}(S(x), S(y)) \leq k d(x, y)$ for all $x, y \in X$ and some $k \in(0,1)$, where $d^{*}$ denotes the Hausdorff metric on the compact subsets of $2^{X}$ generated by the norm $d$, then $S+C: D \rightarrow 2^{X}$ is $\gamma$-condensing.

By homology we mean Cech homology with rational coefficients, and call a compact metric space $Y$ acyclic if it has the same homology as a one point space. In particular, any contractable space is acyclic and thus any convex or star-shaped subset of $X$ is acyclic. A mapping $T: D \rightarrow 2^{X}$ is called acyclic if $T(x)$ is compact and acyclic for each $x \in D$.

The following theorem of Eilenberg and Montgomery [4] together with the succeeding result from [16] will form the basis from which we will deduce our results.

THEOREM A. [4] Let $M$ be an acyclic absolute neighborhood retract (ANR), $N$ a compact metric space, $r: N \rightarrow M$ a continuous singlevalued mapping and $T: M \rightarrow 2^{N} a$ u.s.c. acyclic mapping. Then the mapping 
$r T: M \rightarrow 2^{M}$ has a fixed point, i.e., there exist $x \in M$ such that $x \in r(T(x))$.

LEMmA A. [16] Let $D \subset X$ be closed and convex and $T: D \rightarrow 2^{X}$. Then for each $\Omega \subset D$ there exists a closed convex set $K$, depending on $T, D$, and $\Omega$, with $\Omega \subset K$ and $\overline{\operatorname{co}}\{T(D \cap K) \cup \Omega\}=K$.

Our first result is the following fixed point theorem.

THEOREM 1. Let $X$ be a Frechet space with $D \subset X$ closed and convex. Suppose $T: D \rightarrow 2^{X}$ is u.s.c. and acyclic and $f: W \rightarrow D$ is single-valued and continuous, where $W \supset T(D)$. Iff $T: \mathrm{D} \rightarrow 2^{X}$ is $\Phi$-condensing, then $f$ Thas a fixed point. In particular, if $T(D) \subset D$ and $T$ is $\Phi$-condensing, then $T$ has $a$ fixed point.

Proof. Choose $x_{0} \in D$. By Lemma A, we obtain a closed convex set $K$ such that $x_{0} \in K$ and $\overline{c o}\left\{f(T(K \cap D)) \cup\left\{\dot{x}_{0}\right\}\right\}=K$. Since $f(T(D)) \subset D$, we see that $K \cap D=K$ and so $\overline{c o}\left\{f(T(K)) \cup\left\{x_{0}\right\}\right\}=K$. By the defining properties of the measure of noncompactness $\Phi$, and, since $f T$ is $\Phi$-condensing, $K$ must be compact. In view of the results in $[3,10]$, every compact convex subset of a Frechet space is an ANR, and is acyclic. Consequently, letting $M=K, N=T(K)$, and $f=r$ we may invoke Theorem A to conclude that $f T$ has a fixed point. The last part of the theorem follows by letting $f=$ identity.

REMARK 1. Using the above result, it is clear that a theorem analogous to Theorem 3.4 in [15] is valid for acyclic 1-set and 1-ball contractive mappings.

The second part of Theorem 1 has been obtained in $[7,17]$ for the case when $T$ is compact and $X$ is a Banach space.

TheOREM 2. Let $X$ be a Frechet space and $D \subset X$ open and convex with $0 \in D$. If $T: \bar{D} \rightarrow 2^{X}$ is $a \Phi$-condensing and acyclic mapping such that

$$
T(x) \cap\{\lambda x \mid \lambda>1\}=\varnothing \text { for } x \in \partial D
$$

then $T$ has a fixed point. In particular, if $T(\partial D) \subset \bar{D}, T$ has a fixed point.

Proof. Let $\rho: X \rightarrow \bar{D}$ be the single-valued mapping defiined by: $\rho(x)$ $=x$ if $x \in \bar{D}$, and $\rho(x)=x / p(x)$ if $x \in X \backslash \bar{D}$, where $p$ is the support function of $\bar{D}$. Since $0 \in D$, it follows that $\rho$ is continuous. Furthermore, for each $A \subset X, \rho(A) \subset \overline{\operatorname{co}}\{A \cup\{0\}\}$, so that, by the defining properties of $\Phi$, 
$\Phi(\rho(A)) \leq \Phi(A)$. Hence, $\rho T$ is a $\Phi$-condensing mapping of $\bar{D}$ into $\bar{D}$ because if $\Omega \subset \bar{D}$ and $\Phi(\rho(T(A))) \geq \Phi(\Omega), \Omega$ must be relatively compact. Thus, by Theorem 1, we may choose $x \in \bar{D}$, with $x=\rho(z)$ and $z \in T(x)$, i.e., $x \in \rho T(x)$. It follows from (4) that $x \in T(x)$. Indeed, if $z \in \bar{D}$, then $\rho(z)$ $=z=x$ and so $x \in T(x)$, and if $z \notin \bar{D}$, then $\rho(z)=\beta z$ for some $\beta<1$ and so $(1 / \beta) x \in T(x)$, in contradiction to (4). The last assertion follows from the fact that, for each $y \in \partial D$ and $\beta<1, \beta y \in D$ and so $T(\partial D) \subset \bar{D}$ implies (4).

In case $T(x)$ is convex for each $x \in \bar{D}$, the above result has been obtained in [15] by use of a topological degree argument, without the assumption that $D$ is convex.

1. In case $X$ is a Banach space, whose norm has certain additional properties, we will now prove some results for acyclic mappings $T: D \rightarrow$ $2^{X}$, where $D$ is closed and convex, without the assumption that $T(D) \subset D$. In particular, we strengthen the results of $[8,16]$ for mappings satisfying the so-called "nowhere normal outward" condition and without the assumptions (as in $[8,16]$ ) that $D$ contains a set with a nonempty core and that $X$ is equipped with a collection of approximation maps (see [8] for definitions of these concepts).

We recall that a Banach space $X$ is said to have Property $(H)$ if $X$ is strictly convex and whenever $\left\langle\mathrm{x}_{\mathrm{n}}\right\rangle \subset X$ is such that $\left\langle\left\|x_{n}\right\|\right\rangle \rightarrow\|x\|$ and $\left\langle x_{n}\right\rangle$ converges weakly to $x$, then $\left\langle x_{n}\right\rangle \rightarrow x$. Every locally uniformly convex Banach space has this property. We will use the following lemma concerning such spaces, and use the notation $\left\langle x_{n}\right\rangle \rightarrow x$ to denote the weak convergence of the sequence $\left\langle x_{n}\right\rangle$ to $x$.

Lemma 1. Let $X$ be a reflexive Banach space with Property $(\mathrm{H})$, and suppose $D \subset X$ is closed and convex. Then to each $x \in X$ there exists $a$ unique point $N(x)$ in $D$ such that $\|x-N(x)\|=\inf _{y \in D}\|y-x\|$. Furthermore, the mapping $x \rightarrow N(x)$ is continuous.

Proof. Let $x \in X$ and let $d=\inf _{y \in D}\|y-x\|$. Choose $\left\langle u_{n}\right\rangle \subset D$ such that $\left\langle\left\|u_{n}-x\right\|\right\rangle \rightarrow d$. Then $\left\langle u_{n}\right\rangle$ is a bounded subset of $D$ and since $X$ is reflexive and $D$ is weakly complete we may choose a subsequence $\left\langle u_{n_{k}}\right\rangle$ of $\left\langle u_{n}\right\rangle$ with $\left\langle u_{n_{k}}\right\rangle \rightarrow z \in D$. Since $\left\langle u_{n_{k}}-x\right\rangle \rightarrow z-x$,

$$
d=\lim _{k}\left\|u_{n_{k}}-x\right\|=\lim _{k} \inf \left\|u_{n_{k}}-x\right\| \geq\|z-x\| .
$$

But $\|z-x\| \geq d$, and so $\left\langle\left\|u_{n_{k}}-x\right\|\right\rangle \rightarrow\|z-x\|$. Since $X$ has Property (H) we must have $\left\langle u_{n_{k}}\right\rangle \rightarrow z$. The point $z$ with $z \in D$ and $\|z-x\|=d$ is unique 
because $X$ is strictly convex, and since, by the above argument, any subsequence of $\left\langle u_{n}\right\rangle$ will in turn have a subsequence which converges to $z$, we see that $\left\langle u_{n}\right\rangle \rightarrow z=N(x)$.

We now show that $N$ is continuous. Let $y \in X$ with $\left\langle y_{n}\right\rangle \subset X$ such that $\left\langle y_{n}\right\rangle \rightarrow y$. For each $n$ we have $\left\|y_{n}-N\left(y_{n}\right)\right\| \leq\left\|y_{n}-N(y)\right\|$, so that $\lim \sup \left\|y_{n}-N\left(y_{n}\right)\right\| \leq\|y-N(y)\|$. Since $\left\langle N\left(y_{n}\right)\right\rangle$ is a bounded subset of $D$ we may choose $\left\langle N\left(y_{n_{k}}\right)\right\rangle$ such that $\left\langle N\left(y_{n_{k}}\right)\right\rangle \rightarrow z \in D$. Then

$$
\begin{gathered}
\|y-N(y)\| \leq\|y-z\| \leq \lim \inf \left\|y_{n_{k}}-N\left(y_{n_{k}}\right)\right\| \\
\leq \lim \sup \left\|y_{n_{k}}-N\left(y_{n_{k}}\right)\right\| \leq\|y-N(y)\| .
\end{gathered}
$$

Consequently, $\lim \left\|y_{n_{k}}-N\left(y_{n_{k}}\right)\right\|=\|y-N(y)\|$, and so by the first part of the proof, $\left\langle N\left(y_{n_{k}}\right)\right\rangle \rightarrow N(y)$. This argument shows that any subsequence of $\left\langle N\left(y_{n}\right)\right\rangle$ in turn has a subsequence which converges to $N(y)$, so that $\left\langle N\left(y_{n}\right)\right\rangle \rightarrow N(y)$.

We point out that any uniformly convex Banach space is reflexive and has Property $(\mathrm{H})$.

Following Halpern [8], for a subset $D$ of a Banach space $X$, we define the outward set of a point $x \in D$, denoted by $n_{D}(x)$, to be

$$
n_{D}(x)=\{y \in X \mid y \neq x,\|y-x\| \leq\|y-z\| \text { for all } z \in D\} \text {. }
$$

We add in passing that, as was shown in [9], if $I_{D}(x)$ is the inward set of $x \in X$, i.e., $I_{D}(x)=\{y \in X \mid \lambda x+(1-\lambda) y \in D$ for some $\lambda \in[0,1)\}$, then $n_{D}(x) \cap \overline{I_{D}(x)}=\varnothing$.

Theorem 3. Let $X$ be a Banach space with $D \subset X$ closed and convex. Suppose that $T: D \rightarrow 2^{X}$ is acyclic and "nowhere normal outward," i.e.,

$$
T(x) \cap n_{D}(x)=\varnothing \text { for } x \in D
$$

Furthermore, suppose that one of the following conditions holds:

(i) $X$ is strictly convex and $D$ is compact.

(ii) $X$ is reflexive, satisfies condition $(\mathrm{H})$, and $T(D)$ is compact.

Then $T$ has a fixed point.

Proof. (i) Since $X$ is strictly convex and $D$ is compact, the mapping $N: X \rightarrow D$ defined by the inequality $\|N(x)-x\| \leq\|y-x\|$ for all $y \in D$, is well defined and continuous [8]. Since $D$ is an acyclic ANR, we use 
Theorem A to conclude that $N T$ has a fixed point in $D$. Since $T$ satisfies (5), the fixed point of $N T$ must also be a fixed point of $T$.

(ii) By Lemma 1, the above mapping $N$ is continuous. Since $T(D)$ is relatively compact, $N T$ is condensing, and so $N T$ has a fixed point by Theorem 1. Again, using (1), this fixed point must also be a fixed point of $T$.

COROLlary 1. Theorem 3 holds with the hypothesis "T is nowhere normal outward" replaced by either of the stronger conditions, " $T(x) \subset \overline{I_{D}(x)}$ for all $x \in D$ " or " $T(x) \subset I_{D}(x)$ for all $x \in D$."

In case $T(x)$ is star-shaped for each $x \in \bar{D}$, Theorem 3 has been proved in [8, Theorem 20] under the additional condition that $X$ is equipped with a collection of approximation maps and that the core $(D) \neq \varnothing$.

THEOREM 4. Let $X$ be a Banach space with $D \subset X$ closed and convex. Suppose $T: D \rightarrow 2^{X}$ is acyclic and $\Phi$-condensing. Furthermore, assume that one of the following conditions holds:

(i) $X$ is strictly convex and $T(x) \subset I_{D}(x)$ for $x$ in $D$.

(ii) $X$ is a Hilbert space, $T(x) \cap n_{D}(x)=\phi$ for each $x \in D$, and $\Phi$ is either the ball-measure or the set-measure of noncompactness defined in $\S 1$. Then $T$ has a fixed point.

Proof. (i) Let $x_{0} \in D$. By Lemma A, we may choose a closed convex set $K$ which contains $x_{0}$ and such that $\overline{c o}\left\{T(D \cap K) \cup\left\{x_{0}\right\}\right\}=K$. By previously used arguments, $K$ must be compact. Let $x \in K \cap D$ with $z \in$ $T(x)$. Then $z \in I_{D}(x)$, so that for some $\lambda \in[0,1), \lambda x+(1-\lambda) z \in D \cap K$. This shows that $T(x) \subset I_{D \cap K}(x)$ for each $x \in D \cap K$. Hence, by Corollary 1, $T$ has a fixed point.

(ii) Let $N: X \rightarrow D$ be defined by $\|N(x)-x\|=\inf \{\|z-x\|$ for each $x \in D\}$. Now, $X$ is a Hilbert space, and Cheney and Goldstein [2] have shown that $\|N(x)-N(y)\| \leq\|x-y\|$ for each $x$ and $y$ in $X$. It is not hard to show that this implies that for each $A \subset X, \Phi(N(A)) \leq \Phi(A)$. Consequently, $N T: D \rightarrow 2^{D}$ is $\Phi$-condensing, and hence, by Theorem 1, NT has a fixed point. Since $T(x) \cap n_{D}(x)=\varnothing$, this fixed point must also be a fixed point of $T$.

Under hypothesis (i) the above result strengthens Theorem 3 in [16] and, in particular, Theorem 24 in [8].

Remark 2. If $X$ is a Hilbert space and $D=B \overline{(0,1)}$, then for $x \in \partial D$, $n_{D}(x)=\{\lambda x \mid \lambda>1\}$. Hence for a mapping $T: D \rightarrow 2^{X}$ the Leray-Schauder 
condition (4) of Theorem 2 coincides with the requirement that $T(x) \cap$ $n_{D}(x)=\varnothing$ for all $x \in D$.

\section{REFERENCES}

1. F. E. Browder, The fixed point theory of multivalued mappings in topological vector spaces, Math. Annalen, 177 (1968), 283-301.

2. E. W. Cheney and A. A. Goldstein, Proximity maps for convex sets, Proc. Amer. Math. Soc., 10 (1959), 448-450.

3. J. Dugundji, An extension of Tietze's Theorem, Pacific J. Math., 1 (1951), 353-367.

4. S. Eilenberg and D. Montgomery, Fixed point theorems for multivalued transformations, Amer. J. Math., 68 (1946), 214-222.

5. Ky Fan, Extensions of two fixed point theorems of F. E. Browder, Math. Z., 112 (1969), 234-240.

6. I. T. Gohberg, L. S. Goldenstein and A. S. Markus, Investigations of some properties of bounded linear operators with their q-norms, Uch. Zap. Kishinevsk. In-ta., 29 (1957), 29-36. 7. L. Górniewicz and A. Granas, Fixed point theorems for multivalued mappings of the absolute neighborhood retracts, J. Math. Pures et Appl., 49 (1970), 381-395.

8. B. Halpern, Fixed point theorems for set-valued maps in infinite dimensional spaces, Math. Annalen, 189 (1970), 87-98.

9. B. Halpern and G. Bergman, A fixed point theorem for inward and outward maps, Trans. Amer. Math. Soc., 130 (1968), 353-358.

10. S. T. Hu, Theory of Retracts, Wayne State Univ. Press, 1965.

11. C. Kuratowski, Sur les espaces complets, Fund. Math., 15 (1930), 301-309.

12. T. W. Ma, Topological degree of set-valued compact vector fields in locally convex spaces, Dissertationes Math., 92 (1972), 1-43.

13. R. D. Nussbaum, The fixed point index for local condensing maps, Annali di Mat. Pura et Appl., 89 (1971), 217-258.

14. W. V. Petryshyn, Fixed point theorem for various classes of 1-set-contractive and 1-ball-contractive mappings in Banach spaces, Trans. Amer. Math. Scoc., 182 (1973), 323-352.

15. W. V. Petryshyn and P. M. Fitzpatrick, A degree theory, fixed point theorems, and mapping theorems for multivalued noncompact mappings, Trans. Amer. Math. Soc., 194 (1974), 1-25.

16. Fixed point theorems for multivalued noncompact inward mappings, J. Math. Anal. and Appl., 46 (1974), 756-767.

17. M. J. Powers, Multivalued mappings and Lefschetz fixed point theorems, Proc. Camb. Phil. Soc., 68 (1970), 619-630.

18. S. Reich, Fixed points in locally convex spaces, Math. Z., 125 (1972), 17-31.

19. B. N. Sadovsky, Ultimately compact and condensing mappings, Uspehi Mat. Nauk, 27 (1972), 81-146.

20. T. Van der Walt, Fixed and almost fixed points, Math. Center Tracts, No. 1, 128pp., Amsterdam, 1963.

Received May 16, 1973. Supported in part by the NSF Grant GP-20228.

RUTGERS UNIVERSITY

Current address: $\quad$ P. M. Fitzpatrick

Department of Mathermatics

University of Chicago 



\section{PACIFIC JOURNAL OF MATHEMATICS}

\section{EDITORS}

RICHARD ARENS (Managing Editor)

University of California

Los Angeles, California, 90024

\section{R. A. BEAUMONT}

University of Washington

Seattle, Washington 98105

\section{J. DugunDJI}

Department of Mathematics University of Southern California Los Angeles, California 90007

D. Gillbarg AND J. MilgRAM

Stanford University Stanford, California 94305

\section{ASSOCIATE EDITORS}

E. F. BECKENBACH

B. H. NEUMANN

SUPPORTING

UNIVERSITY OF BRITISH COLUMBIA

UNIVERSITY OF CALIFORNIA

MONTANA STATE UNIVERSITY

UNIVERSITY OF NEVADA

NEW MEXICO STATE UNIVERSITY

OREGON STATE UNIVERSITY

UNIVERSITY OF OREGON OSAKA UNIVERSITY
F. WOLF

K. YosHIDA

INSTITUTIONS

UNIVERSITY OF SOUTHERN CALIFORNIA

STANFORD UNIVERSITY

UNIVERSITY OF TOKYO

UNIVERSITY OF UTAH

WASHINGTON STATE UNIVERSITY

UNIVERSITY OF WASHINGTON

AMERICAN MATHEMATICAL SOCIETY

NAVAL WEAPONS CENTER

The Supporting Institutions listed above contribute to the cost of publication of this Journal, but they are not owners or publishers and have no responsibility for its content or policies.

Mathematical papers intended for publication in the Pacific Journal of Mathematics should be in typed form or offset-reproduced, (not dittoed), double spaced with large margins. Underline Greek letters in red, German in green, and script in blue. The first paragraph or two must be capable of being used separately as a synopsis of the entire paper. Items of the bibliography should not be cited there unless absolutely necessary, in which case they must be identified by author and Journal, rather than by item number. Manuscripts, in duplicate if possible, may be sent to any one of the five editors. Please classify according to the scheme of Math. Rev. Index to Vol. ${ }^{39}$. All other communications to the editors should be addressed to the managing editor, or Elaine Barth, University of California, Los Angeles, California, 90024.

100 reprints are provided free for each article, only if page charges have been substantially paid. Additional copies may be obtained at cost in multiples of 50 .

The Pacific Journal of Mathematics is issued monthly as of January 1966. Regular subscription rate: $\$ 72.00$ a year (6 Vols., 12 issues). Special rate: $\$ 36.00$ a year to individual members of supporting institutions.

Subscriptions, orders for back numbers, and changes of address should be sent to Pacific Journal of Mathematics, 103 Highland Boulevard, Berkeley, California 90708.

\section{PUBLISHED BY PACIFIC JOURNAL OF MATHEMATICS, A NON-PROFIT CORPORATION}

Copyright (C) 1974 by Pacific Journal of Mathematics

Manufactured and first issued in the U.S.A. 


\section{Pacific Journal of Mathematics}

\section{Vol. 54, No. $2 \quad$ June, 1974}

John Edward Coury, Walsh series with coefficients tending monotonically to

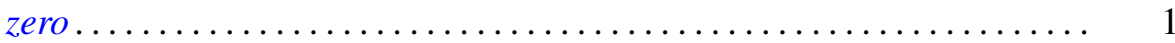

Patrick Michael Fitzpatrick and Walter Volodymyr Petryshyn, Fixed point theorems for multivalued noncompact acyclic mappings ............

Irving Leonard Glicksberg, More on Phragmén-Lindelöf for function

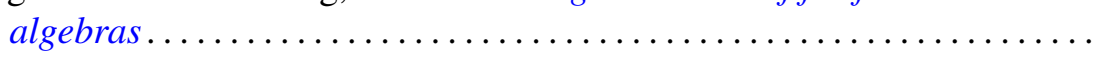

Adilson Goncalves, Structural constants. II .................. 39

Richard P. Gosselin, Closure theorems for affine transformation groups .... 53

Ralph Peter Grimaldi, Baer and UT-modules over domains ........... 59

Edward Grossman, On the prime ideal divisors of $\left(a^{n}-b^{n}\right) \ldots \ldots \ldots \ldots . \ldots 73$

A. Hedayat and Ester Seiden, On the theory and application of sum composition of Latin squares and orthogonal Latin squares.......... .

Gerald L. Itzkowitz, Continuous measures, Baire category, and uniform continuity in topological groups ......................... 115

Francis Masat, Right simple congruences on a semigroup ............ 127

Robert Harvey Oehmke, Right congruences and semisimplicity for Rees matrix semigroups..................................

Qazi Ibadur Rahman and Jan Stankiewicz, Differential inequalities and local valency . . . . . . . . . . . . . . . . . . . . . . . . . . . . . . . . . . . . . 165

William John Reed, Random points in a simplex ................ 183

Mohan S. Shrikhande, Strongly regular graphs and group divisible

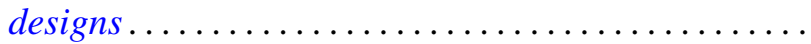

Zahava Shmuely, The structure of Galois connections ... . .

Robert C. Shock, Dual generalizations of the Artinian and Noetherian

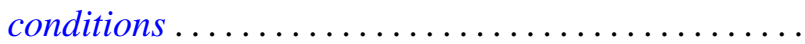

Arne Stray, Approximation and interpolation for some spaces of analytic functions in the unit disc ........................

Eldon Jon Vought, Monotone decompositions into trees of Hausdorff continua irreducible about a finite subset ............

James Wirth, The mapping cylinder axiom for WCHP fibrations ... 263

Gordon S. Woodward, Invariant means and ergodic sets in Fourier analysis... 